\title{
COMMUNICOLOGY FROM THE 'PORTALS' PERSPECTIVE: A SUMMATIVE-SCHEMATIC VIEW
}

\author{
STANISŁAW PUPPEL
}

\begin{abstract}
Communicology as a universal design is shown here as a phenomenon/process which can be accessed from a number of 'portals'. Communicology as a design is defined as pluripotent and composed of five sphere-shaped components which contain universal and specific content. The content is assumed to embrace the totality of human communicative practices. The exposition of the content of the paper is presented in the form of summative schematics.
\end{abstract}

Key words: portal, communicology, pluripotent communicology design, sphere-shaped components, synergy

\section{Introduction}

Communicological research has widened the subdiscipline of applied linguistics considerably by focusing on the dynamics of inter/transpersonal, inter/transinstitutional and inter/transcultural contacts and by bringing to the fore the various environmental constraints which are present in human communicative practice. In particular, the dynamism of natural language use, necessarily embedded in the environmental pressures of all kinds, has allowed to broaden the concept of 'human communication' as a very special, human genus-centered activity. It may be viewed not only as a sender-receiver process (cf. Shannon and Weaver, 1949; Cherry, 1980) but also as a complex process of cross-environmental interrelations (and unavoidable interventions) where the environmental constraints are basically cultural (or cross-cultural) constraints. The cross-environmental constraints may serve as both 
potential igniters and environmental actuators of a multifarious richness of communicative acts performed in ever changing environmental (i.e. contextual) variations. It is, therefore, understandable to view the phenomenon of communication as representing not only some kind of a communication system in use (e.g. 'language' in the human milieu), but also as representing a necessary supplement to it in the form of the 'environmental framework' meant as a complex of highly changeable conditions of its occurrence.

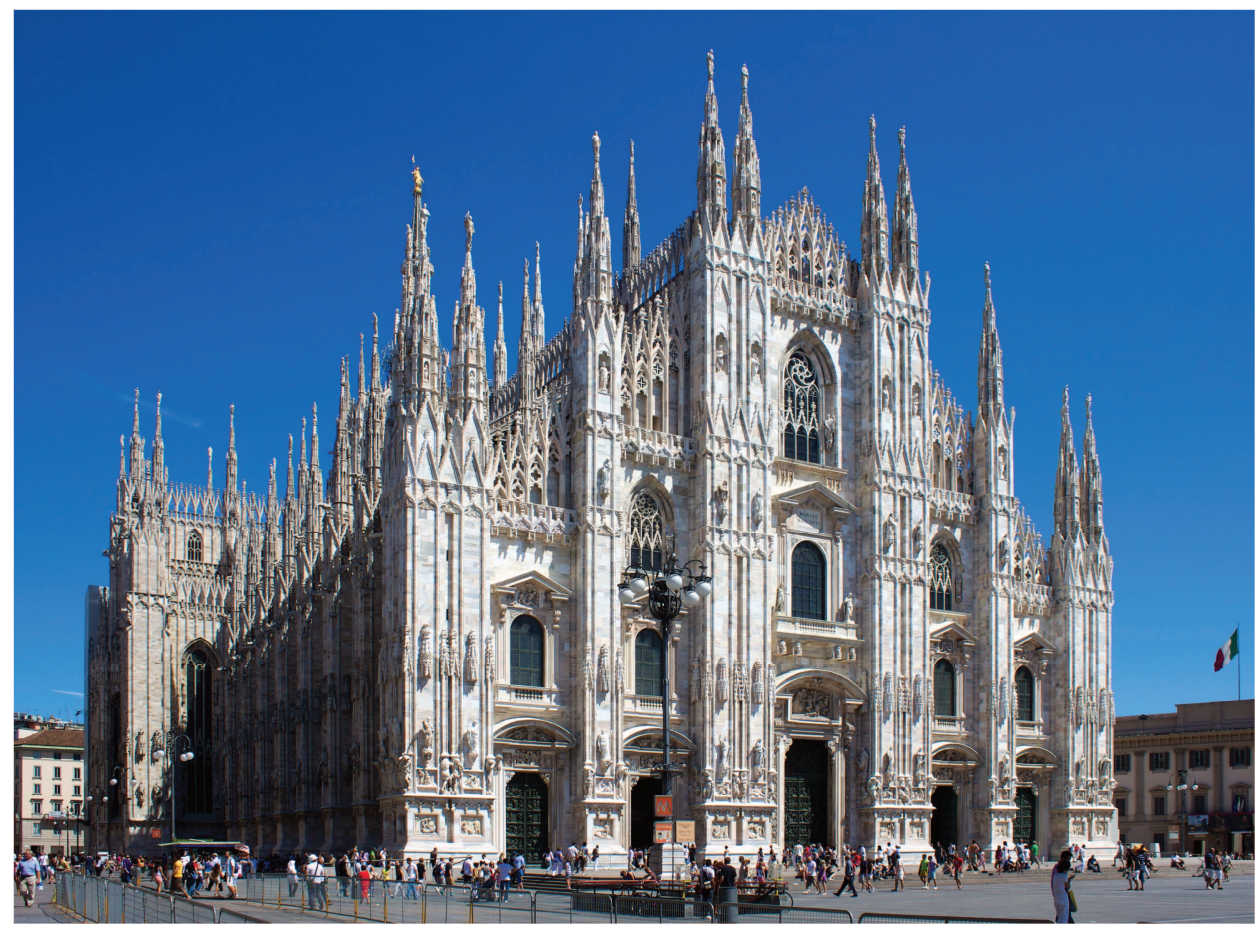

Fig. 1. A photo of the Milan Cathedral as an instance of a complex architectural design which can serve as a metaphor of the communicology design. As can be seen, the cathedral can be entered via a number of portals. Some of them, including the main portal, are visible in the façade of the edifice (source of the photo: Milano_duomo_1865_resize)

In this unavoidably dual framework of 'system/language-environment', the notion of communication may simply serve as some kind of a design, or a well defined 'site' (or larger communicative space epitomized by the notion of 'architectural design') where various communicative entities/agents/phenomena may be encountered. It in this vein that communicology will be approached in the present article, namely that the very concept of 'human communication' may be regarded as some kind of a complex edifice which, like many architectural buildings, may be accessed 
by means of a number of 'portals' leading to these entities/agents/phenomena. The latter not only reside in it but they are also collectively responsible for determining the richness of human communicative practices. In this respect, communicology may indeed be likened to an image of a cathedral as a metaphor of a complex spatial design to whose interior a number of portals lead thus allowing the interested visitor to move along and across its expanse (see Fig. 1), while at the same time experiencing the wholeness of the edifice.

The 'portals' perspective to communicology entertained and proposed in the present paper is based on the following premises:

1. An edifice is a complex structure (architectural design) whose interior may be accessed via a number of portals, main and accessory (see e.g. Szolginia, 1992; Ching, 1997, on the portal as an architectural element).

2. Communicology as a universal design (referred to here as the 'communicology design', hence CD) may be likened to a complex edifice composed of many interrelated 'feeder components' which can be accessed via a number of 'portals' and which can thus be approached and studied separately.

3. The feeder components of the CD contain their own 'interiors' (or content).

4. The feeder components of the CD are interrelated by a sequence of 'portals'.

5. The 'portals' in the CD lead to a number of component interiors of growing specificity and necessarily connect them into a functional and highly synergetic whole.

6. The synergetic whole of the $\mathrm{CD}$ functions as a pluripotent design and as such it is responsible for (determines) all the communicative practices, both subhuman, and, particularly, the human practices.

7. Naturally, the human communicative practices, owing to the presence of the uniquely human verbal - non-verbal complex generated by the $\mathrm{CD}$, are, in evolutionary terms, the latest extension of the universal communicative potential which is represented by and contained within the Universal Communication Space encountered on Earth (see Puppel, 2004).

\section{The Communicology design (CD) as a linear composition of spheres}

It is assumed that communication occurs on Earth as the only carrier of all embodied communicative practices. More precisely, communication is both subsolar (i.e. it occurs under the Sun) and supraterrestrial (i.e. it occurs generally on the surface of the Earth, both in the aearial and aquatic conditions).

It is further assumed that the totality of the $\mathrm{CD}$ requires the presence of the following spheres as decisive factors in the generation of the multiplicity of communicative acts: 
- the sphere of the 'grand design of life' (I/GDL), where the phenomena of human embodiment, cohabitation, interactivity, and communication are contained,

- the sphere of the 'imperial tetragon of embodiment' (II/ITE), where an interplay of the parameters of militancy, trade-offs, utility, and display of every human communicator is contained,

- the 'archisphere' (III), which comprises the relational phenomena of holarchy, panarchy, hierarchy, heterarchy, and logarchy as overall rules of connectivity,

- the 'semiosphere' (IV), which contains an underlying semiotic framework and which comprises the concepts of object, concept, name (symbol), and index/icon,

- the sphere of the individual 'human communicating agents as the lords of the rings' (V/HCA as LR), which contains the socially accumulated language and non-language resources, navigable communicative spaces, communicative styles, communicative niches, the immersive socio-cultural dimension, the communicative energy dimension, and the emotional dimension, all determining the human communicative practices,

- in addition, each sphere is assumed to contribute to the integrative and synergetic complex of multiple identities which determine every communicator. These identities comprise the following: the biological identity of every human communicator, the embodied identity, the rule identity, the semiotic identity, and the human communicating agent (HCA) identity.

A mere linear composition of spheres may be illustrated in the following way (Fig. 2):

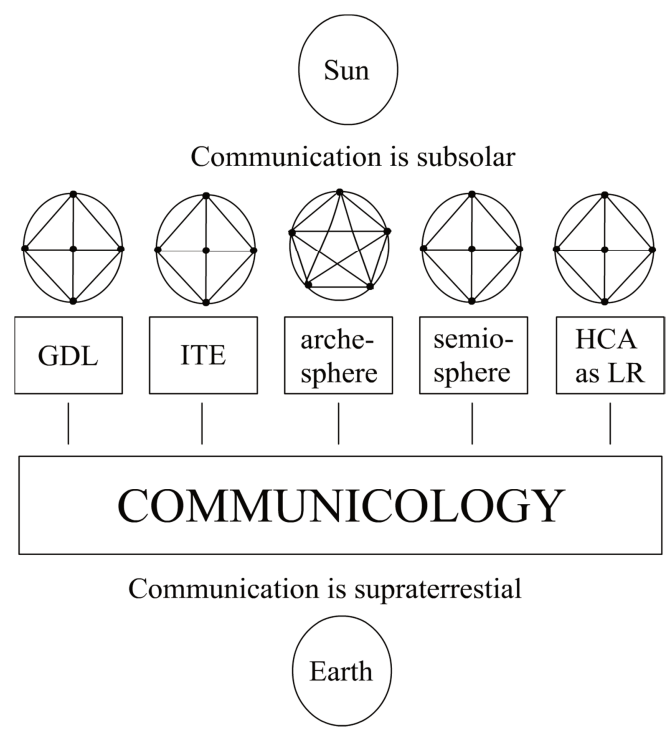

Fig. 2. A linear composition of the five spheres which determines the pluripotent Communicology Design (CD) 


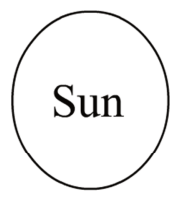

GDL (I)

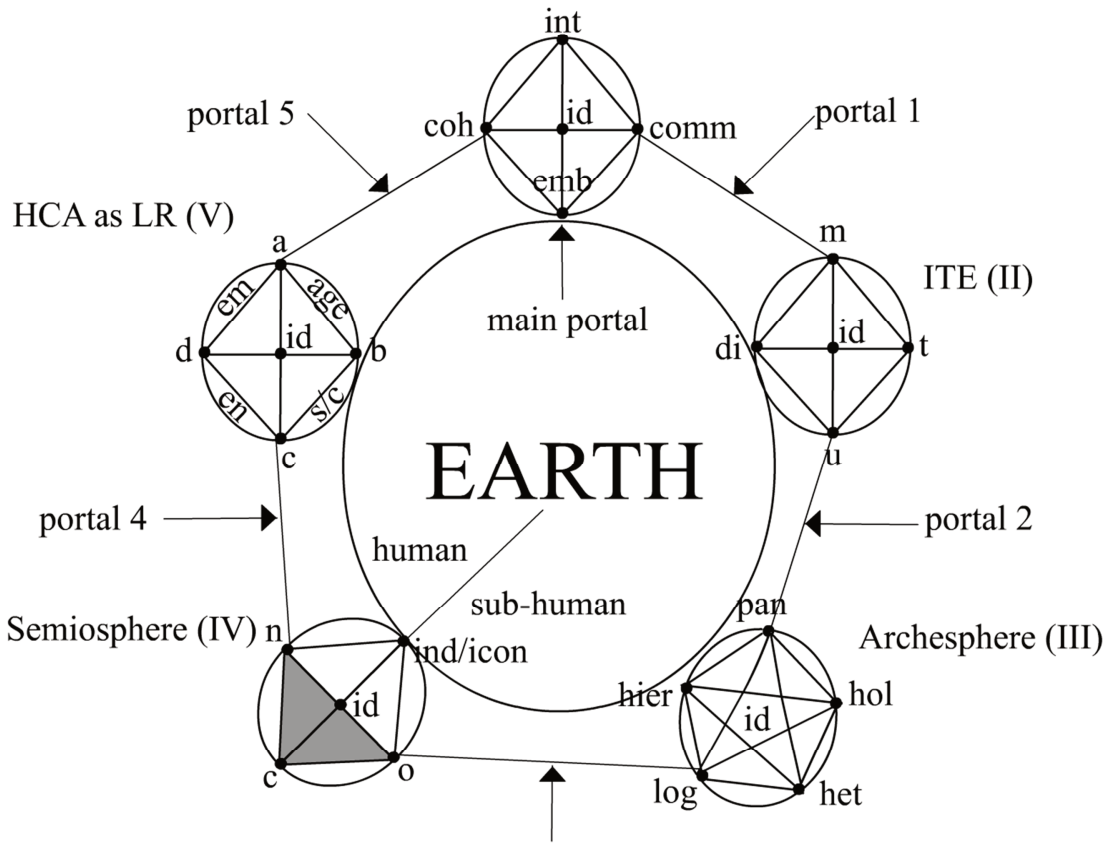

portal 3

GDL - Grand Design of Life

ITE - Imperial Tetragon of Embodiment

HCA - Human Communicating Agent

LR - Lord of the Rings

Emb - embodiment

Coh - cohabitation

Int - interactivity

Comm - communication

$M-$ militancy

$T$ - trade-offs

$U$ - utility

$\mathrm{Di}$ - display

Hol - holarchy

Pan - panarchy

Het - heterarchy

Hier - hierarchy

Log - logarchy
Legend:

$$
\begin{aligned}
& \mathrm{O} \text { - object } \\
& \mathrm{C} \text { - concept } \\
& \mathrm{N} \text { - name } \\
& \text { Ind - index } \\
& \text { a - resources } \\
& \mathrm{b} \text { - navigable spaces } \\
& \mathrm{C} \text { - communicative styles } \\
& \mathrm{d} \text { - communicative niches } \\
& \text { s/c - socio-cultural dimension } \\
& \text { En - energy dimension } \\
& \text { Em - emotional dimension }
\end{aligned}
$$

Multiple identities:

I - biological identity

II - embodied identity

III - rule identity

IV - semiotic identity

$\mathrm{V}-\mathrm{HCA}$ identity

Fig. 3. The Communicology Design (CD) as a connected pentagon with the Earth at its centre and a number of portals, the main and the accessory ones, which have been indicated by means of arrows 
As indicated above, the concept of the portals perspective applied here requires that the five spheres be positioned around the Earth as the fundamental carrier and that the portals be clearly indicated. This is shown in the diagram presented below (Fig. 3) where the CD is presented as a connected pentagon, with the Earth at its centre and with the portals, the main portal and the accessory portals (portals 1-5), properly indicated.

The portals perspective shown above emphasizes the componential structure of the communicology design. As such, it is assumed to demonstrate their necessary, complex and integrative partnership involved in generating the richness of human highly adaptive communicative behaviours. Therefore, if recourse is made to communication behaviours as responsible for the generation of indispensable and inescapable communicative images, one needs to consider the complex nature of the communicology design as has been proposed above.

\section{References}

Cherry, C. 1980/1957. On human communication: a review, a survey, and a criticism. Cambridge, Mass.: The MIT Press.

Ching, F. 1997. A visual dictionary of architecture. New York: Van Nostrand Reinhold.

De Puydt, P.E. 1860. Panarchie. Bruxelles: Trimestrielle.

Gunderson, L.H. and C.S. Holling. (eds.). 2001. Panarchy: understanding trasformations in human and natural systems. Washington, D.C.: Island Press.

Holling, C.S. 2001. „Understanding the complexity of economic, ecological, and social systems”. Ecosystems 4. 390-405.

Koestler, A. 1967. The ghost in the machine. London: Hutchinson.

Nöth, W. 1995. Handbook of semiotics. Bloomington: Indiana University Press.

Puppel, S. 2004. „An outline of a domain-resource-agent-access-management (DRAAM) model of human communication: towards an ecology of human communication". Poznań: Adam Mickiewicz University, Department of Ecocommunication. Electronic Journal Oikeios Logos 1. 1-27.

Puppel, S. 2013a. „Notes on the nature of human sociality”. In Migdał, J. and A. Piotrowska-Wojaczyk. (eds.). Cum reverentia, gratia, amicitia... Księga jubileuszowa dedykowana Profesorowi Bogdanowi Walczakowi. Poznań: Wydawnictwo Rys. 61-67.

Puppel, S. 2013b. „The 'imperial' life of natural languages”. In Gabryś-Barker, D., E. Piechulska-Kuciel and J. Zybert. (eds.). Investigations in teaching and learning languages. Studies in honour of Hanna Komorowska. Heidelberg: Springer-Verlag. 3-8.

Puppel, S. 2017. ECOLI[S $]^{2}$. Essays and notes on ecolinguistic synergy and synthesis. Scripta de Communicatione Posnaniensi. Prace Naukowe Katedry Ekokomunikacji UAM. Tom VIII. Poznań: Zakład Graficzny UAM.

Shannon, C.E. and W. Weaver. 1949. The mathematical theory of communication. Urbana: University of Illinois Press.

Simon, H.A. 1974. „The organization of complex systems”. In Pattee, H.H. (ed.). Hierarchy theory: the challenge of complex systems. New York: Braziller. 3-27.

Szolginia, W. 1992. Architektura. Warszawa: Sigma NOT. 